\title{
Control of isolated microgrid based renewable energy generation using PID controller
}

\author{
Regad Mohamed Sidi Brahim, M'hamed Helaimi, Rachid Taleb \\ Laboratoire Génie Electrique et Energies Renouvelables (LGEER), Electrical Engineering Department, Hassiba \\ Benbouali University, Chlef, Algeria
}

\section{Article Info \\ Article history: \\ Received Sep 10, 2020 \\ Revised Oct 14, 2020 \\ Accepted Oct 19, 2020}

\section{Keywords:}

Frequency control

Genetic algorithm

Microgrid

Particle swarm optimization

PID controller

Renewable energy

\begin{abstract}
This paper investigates optimal PID controller tuning using particle swarm optimization for frequency control in the microgrid system. The proposed microgrid composed of renewable sources such as wind turbine generation and solar system with diesel engine generator and storage systems such as the battery, flywheel, aqua electrolyze, and fuel cell. The microgrid based on renewable energy sources faces different challenges in operation and stability due to the stochastic nature of solar radiation and wind speed that depend upon the weather conditions. Among these challenges, the frequency and power deviations are affected by the sudden unbalance between generation and load which require a suitable and adequate regulation. The principal objective of this study is to reduce the frequency and power deviation by the use of the PID controller optimized based particle swarm optimization due to its simplicity and flexibility to overcome this kind of issues. The simulation results show the better performances and robustness of the proposed controller against the disturbances in load and generations in comparison to using a genetic algorithm.
\end{abstract}

This is an open access article under the $\underline{C C B Y-S A}$ license.

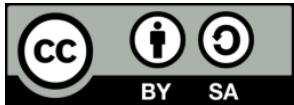

\section{Corresponding Author:}

Regad Mohamed Sidi Brahim

Laboratoire Génie Electrique et Energies Renouvelables (LGEER)

Electrical Engineering Department

Hassiba Benbouali University, Chlef, Algeria

Email: m.reggad@univ-chlef.dz

\section{INTRODUCTION}

Due to the increase of the population around the world, the need for power and the greenhouse crisis lead towards the using renewable energy sources as a distributed generation in isolated areas or interconnected with the main grid. The use of a microgrid system based on renewable energy generation attracts the attention of researchers around the world due to the high cost of fossil fuel and the problem related to gas emission which affects the environment. The microgrid system presents a principle part of the electrical system to prove the electricity in remote and isolated areas where not the availability of the main grid [1]. The use of a hybrid energy system presents a better solution to fossil depletion and greenhouse problems [2]. The microgrid widely consists of renewable energy sources along with storage devices and conventional sources. The better configuration of microgrid includes more than one renewable source such as wind and solar for ensuring the service continuity to supply the demand over time. The microgrid interconnected different distributed generation sources with loads to work autonomously and supply power to their loads [3]. A survey on microgrid presents different structures and topologies of the microgrid system and its applications as reported in [4]. 
These renewable sources have intermittent nature what is made the integration of energy storage devices like aqua electrolyser, battery, flywheel, and fuel cell an important solution to reduce the mismatch between generations and loads [5-11]. The Diesel Engine Generator is integrated as a secondary source that enhances renewable sources when a sudden change occurs in wind speed and solar radiation. One of the most utilities of the use of microgrid is to reduce the energy cost and the greenhouse emissions as presented by Kazem et al. [5] where the others concluded that the interconnection of distributed generation with storage devices and diesel generator improves the energy cost and limit the gas emission. Others papers interests to study the technic-economic assessment in the microgrid system as reported by Al-Waeli et al. [6] that shows the improvement of grid-connected to the PV system. Few researchers interest to study the microgrid stability in presence of a sudden change in loads and generation and its effect on the performances of microgrid operation. Pandey et al. [7] present a hybrid power system to control the frequency with variation in load power and interconnection of two areas. The present paper aims to study the effect intermittent nature of energy generation and load disturbances on the frequency stability of the microgrid system is an isolated mode of operation. The storage devices present an efficient role in the control of microgrid by eliminating the mismatches between load and generation and release the stored power when the load requires it [8]. The intermittent nature of wind and solar energy system provoke frequency and power fluctuations which require an adequate control system [9].

Various control strategy such as the classical PID, fuzzy logic and fractional-order PID is applied for the frequency and power deviations control [10-12]. The classical PID controller is considered the simplest and easiest to be implemented in the kind of system and it is also largely used in the industry process [13-15]. Kumari and Jha [16] studied the control of stand-alone microgrid based battery energy storage devices through the application of particle swarm optimization (PSO) method. Also in [17-18], the authors presented a paper about the frequency control in the hybrid power system using PID/PI based GA. An optimization method called MBA presented by Wang et al. [19] to determine the PID controller gains for a microgrid power system. To solve this problem of frequency control in microgrid by the application of different control strategies like PID controller as in Ray et al. [8]. To determine the values of the gains of the proposed PID controller the PSO method is investigated to be employed. Kennedy and Eberhart in 1995 [20] investigated this method which is known as the stochastic search to resolve difficult optimization issues during a short time and rapid convergence characteristic [21].

The main problem to apply this controller is to determine its optimal parameters. Recently some optimization techniques like genetic algorithm and Particle Swarm Optimization are investigated to overcome the issue of frequency and power deviations in the microgrid system [22-23]. The PSO technique has not got enough application in the field of hybrid energy. This present paper addresses the PID controller of frequency control in an isolated microgrid area. The control technique involves the PID controller tuned using the PSO algorithm. The results present better robustness of PID-PSO in comparison with PID-GA. The rest of this paper is summarized in the fellow sections; the proposed microgrid is presented in section 2 . The control scheme is addressed in section 3. Section 4 shows an overview of the PSO optimization technique. The results and discussion are displayed in section 5. This paper is finished by a conclusion in section 6 and references.

\section{PROPOSED SYSTEM CONFIGURATION}

This study focuses on the use of isolated microgrid including renewable sources like PV and Wind generators with a conventional source like DEG used as secondary sources that can regulate the frequency when the imbalance between generation and load occurs through secondary loop control. The distributed sources are usually interfaced with electronic devices to facilitate the exchange of power between different components like charge and discharge of storage devices. When the load decreases the surplus power from wind and/or photovoltaic, the storage devices start to charge and as well as the power in DEG decreases. From literature, many simplified models of microgrid using small-signal analysis responses of a microgrid are investigated, where all components are presented by a first-order transfer function which has been considered sufficient for frequency behavior analysis and for also simplifies the simulation process [20-21]. The proposed microgrid system is modelled by the first-order transfer function of energy generation and storage devices as shown in Figure 1. The system is modelled for analysis of frequency and power behavior. A control technique must be investigated to improve system performances and stability [23]. 


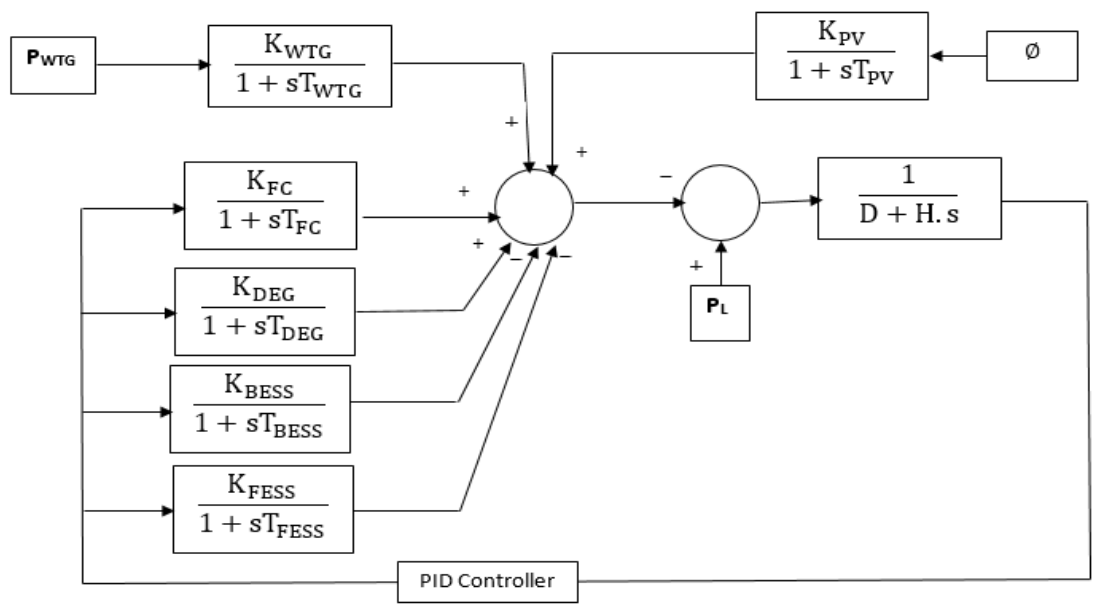

Figure 1 Block of the proposed microgrid system

\section{PROPOSED SYSTEM CONFIGURATION}

The PID controllers have been used in many process controls. With an easy implementation structure, they can assure the best robustness and stability of the system. The PID controller is considered as the most control scheme used to enhance the dynamic performance and reduce error in frequency system. Adding the derivative action is to improve the system performances. The integral action increases the system stability by adding a pole at origin and therefore reducing the steady-state error. The transfer of the proportional-integral-derivative (PID) controller is given by [16].

$$
T F_{P I D}=K_{P}+\frac{K_{I}}{s}+K_{D} \cdot S
$$

where, $K_{P}, K_{I}$, and $K_{D}$ are the proportional, integral and derivative gain of PID the controller respectively. The structure of the PID controller is presented in the Figure 2 [24].

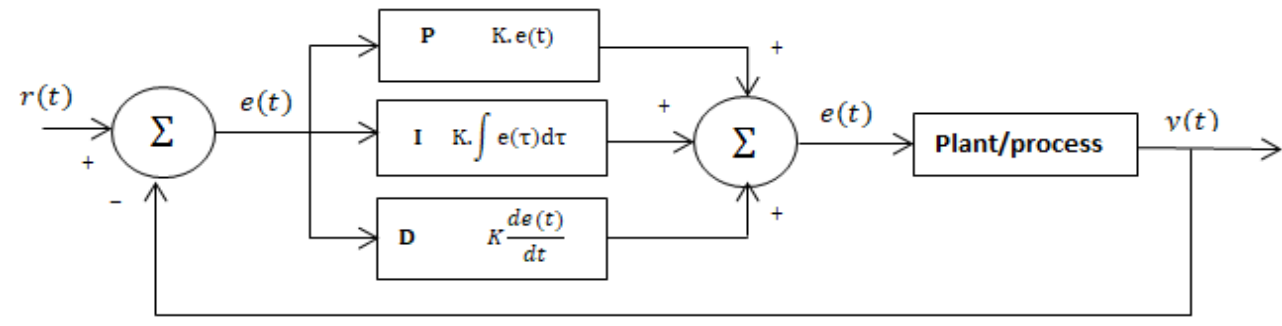

Figure 2. Structure of the PID controller

Parameters of the PID controller are optimally tuned by considering frequency and power deviations. Objective function has been considered for solving any problem plays an efficient role to improve the dynamic response of the system. Hence integral square error (ISE) is considered as a suitable objective function for tuning controller parameters [19].

$$
J=I S E=\int_{0}^{T_{\operatorname{sim}}}\left(\Delta F^{2}\right) d t
$$

where $\Delta F$ is the system frequency deviation of the microgrid. The $T_{\operatorname{sim}}$ is the time simulation. This objective function will be resolved using the PSO algorithm to determine the optimal parameters of the PID controller.

\section{PARTICLE SWARM OPTIMIZATION(PSO)}

Various functions have not been able to be resolved by analytical methods that give the solutions in short duration. To overcome these types of problems some optimization methods are investigated to offer an

Control of isolated microgrid based renewable energy generation using ... (Regad Mohamed Sidi Brahim) 
approached solution after little iteration [15]. One of the most optimization methods, the particle swarm optimization algorithm is largely used and employed in many fields of optimization issues. This technique a stochastic optimization algorithm simulated by the social attitude and fish schooling of bird flocking investigated by Eberhart and Kennedy. Each particle can be considered as a possible solution for the unknown parameters of the problem to be resolved [16-17]. The $\mathrm{N}$ particles compose the swarm move in search space for D-dimensional. A random position and a random velocity are initialized for each particle. The new velocity is determined by this formula [24].

$$
\begin{aligned}
& V_{i+1}=w \cdot V_{i}+C_{1} \cdot r_{1}\left(P_{\text {best }}-X i_{k}\right)+C_{2} \cdot r_{2 .}\left(G_{\text {best }}-X_{i}\right) \\
& X_{i+1}=X_{i}+V_{i+1}
\end{aligned}
$$

where $V_{i}$ is velocity dimension of the particle in iteration $i, X_{i}$ is the component in the dimension of the particle position in iteration $i, C_{1}$ and $C_{2}$ are constant weight factors and $r_{1}$ and $r_{2}$ are considered as random factors varied in $[0,1]$. Pbest presents the best position reached so far by particle, Gbest presents the best position reached by the neighbors of the particle, and w presents an inertia weight which is varied between a high value (w0) and decreases to $W_{k+1}=\beta . W_{k}$.

Steps for PSO based controllers' parameters optimization is explained as follow [23].

Step 1: A population of particles is initialized with positions and velocities in the research space.

Step 2: The objective function is calculated for each particle in the research space

Step 3: The evaluated objective function is compared to the best previous values. When the better is the current one, then set the best the current value is replaced by the previous one, and pi equals to the current location xi in D dimensional space.

Step 4: Identify the particle in the neighborhood with the best objective function value so far, and assign its index to the variable $g$

Step 5: Update the particle position and velocity value according to (3) and (4)

Step 6: Repeat step 2 and verify if the criterion is reached or iterations ended

The PSO algorithm flowchart is displayed in Figure 3.

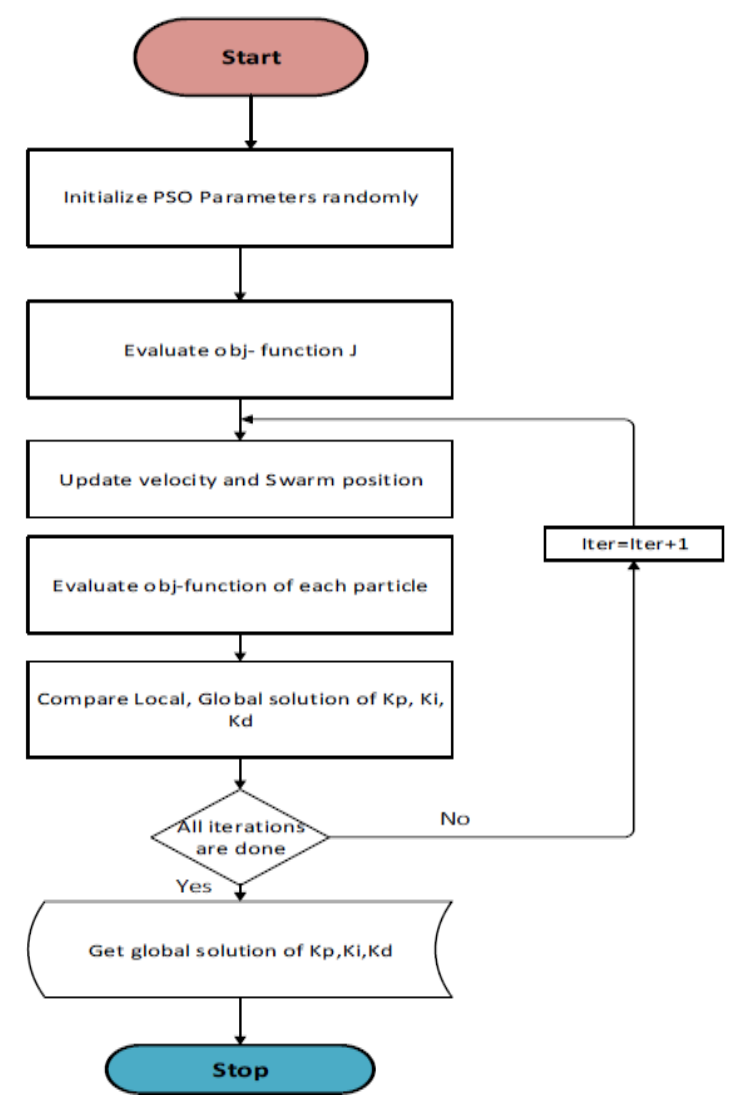

Figure 3. Flowchart of particle swarm optimization 


\section{RESULTS AND DISCUSSION}

The given model in Figure 1 is designed in Simulink using a first-order transfer function. The system is simulated for 100 s under variations in generation power and load as shown in followed figures. The generated power from renewable energy sources and load demand is presented in Figure 4. The PID controller is tuned using the PSO algorithm which its fitness function is shown in Figure 5 and has been fast converged behavior. Frequency and power deviations that demonstrate the robustness of the PSO optimized PID controller in terms of performance indices are presented in Figure 6. The results reflect good stability and reliability of proposed microgrid through the employment of a PID controller tuned by the PSO algorithm in comparison with GA.

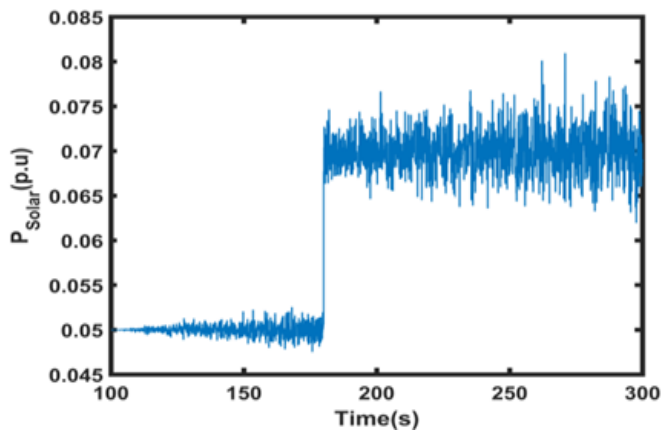

(a)

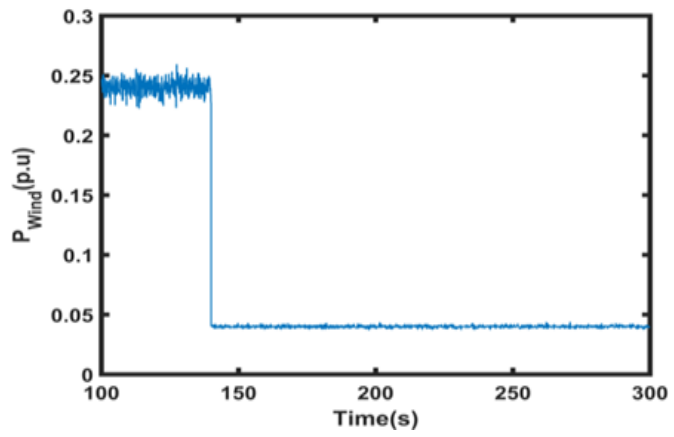

(b)

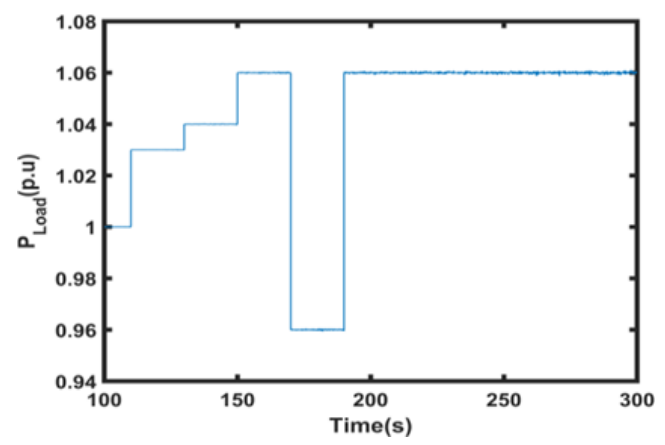

(c)

Figure 4. The output powers of SPV, WTG and load demand, (a) Solar power, (b) Wind power, (c) Load power

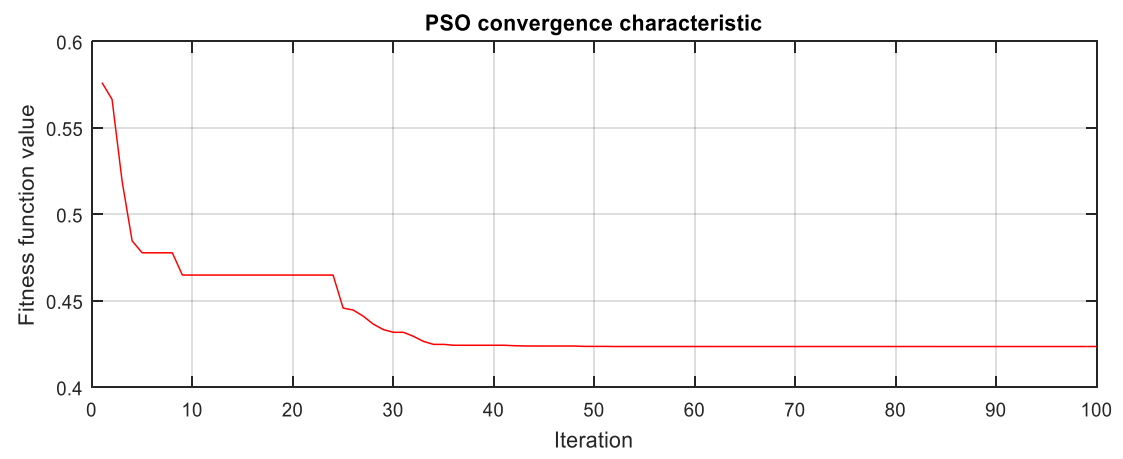

Figure 5. The plot of the fitness function of the PID controller using PSO

\subsection{Time-domain analysis}

In this subsection, a comparison between PSO and GA based PID is accomplished for frequency and power deviations. The system frequency and power are regulated by the PID controller and the results are reported as in Figure 6.

Control of isolated microgrid based renewable energy generation using ... (Regad Mohamed Sidi Brahim) 


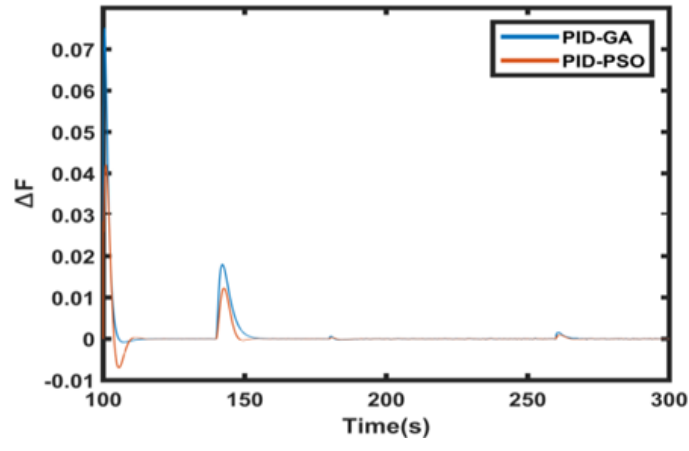

(a)

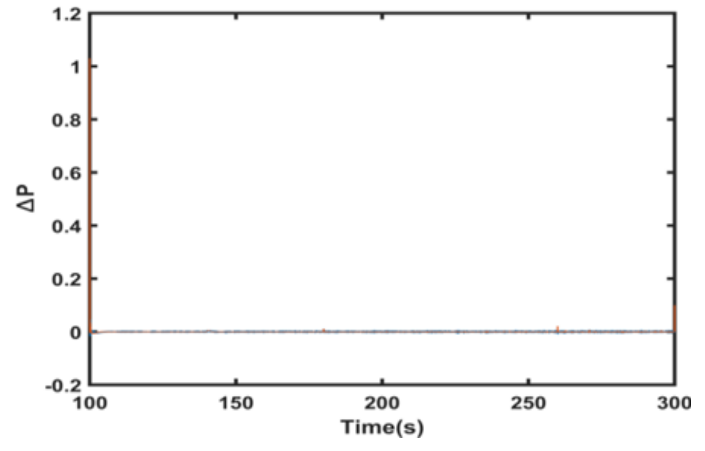

(b)

Figure 6. Frequency and power deviations with best PID controller-based GA and PSO,

(a) Frequency deviation, (b) Power deviation

\subsection{Generated power from microgrid components}

The corresponding power from energy storage devices such as the battery energy storage system and flywheel energy storage system with diesel engine generator are presented in Figure 7 using the PID controller optimized by particle swarm optimization and genetic algorithm. The results show the better performances of the system using PSO in comparison with GA. The controller can reduce the fluctuation in generation power caused by the disturbances in both generation power from renewable sources and load power.

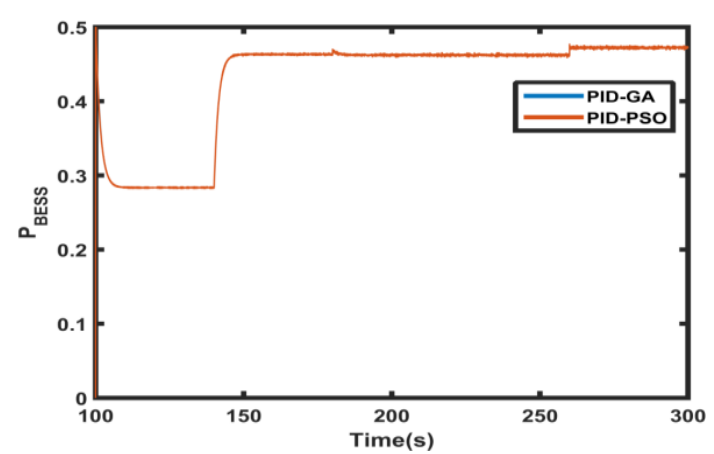

(a)

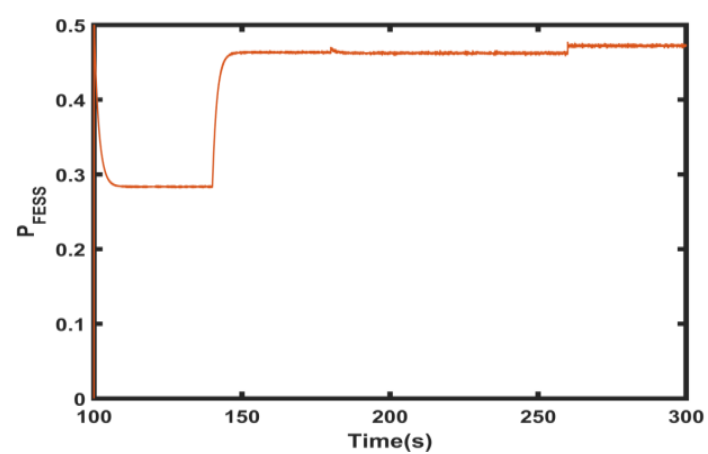

(b)

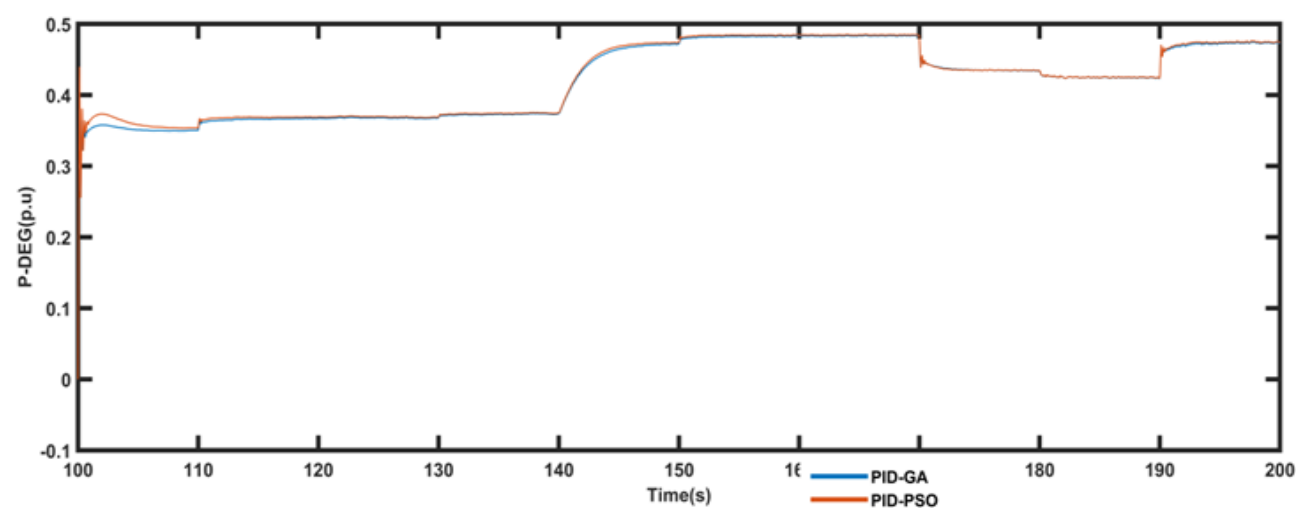

Figure 7. The output power of DEG, BESS and FESS with the best PID controller, (a) Output power of BESS, (b) output power of FESS, (c) output power of DEG

Figure 7 show the frequency control in time domain analysis of microgrid. The results show the fast convergence of the PSO to find the optimal PID controller parameters. The best obtained PID controller 
parameters reduce the frequency and power fluctuation against the stochastic variations in power generation from the renewable sources and loads demand perturbations. The sudden change in generation and load affect the frequency and power stability and the controller work to reduce this effect by the feedback signal to the storage devices and secondary source DEG. The aforementioned results show up that the PSO algorithm enhances the system performances better than GA in the reduction of frequency fluctuation and convergence to the optimal parameters of the proposed controller.

\section{CONCLUSION}

this paper addresses the frequency control of an isolated microgrid consists of a wind turbine generator, solar power system, battery, flywheel, aqua electrolyze, diesel engine generator, and fuel cell. All microgrid components are modelled by the transfer function in the first order. The PID controller robustness under both intermittent natures of renewable generation and load changes is demonstrated. The frequency deviation is reduced through the application of the PID controller. The optimal gains of the PID controller are achieved using PSO and genetic algorithm. The obtained results show better performances of the proposed control scheme in terms of less oscillation and good system stability. The generated powers by BESS, FESS and DEG are enhanced through the application of PID controller based PSO in comparison with GA. The PID-PSO outperforms PID-GA to mitigate the fluctuation in frequency and power deviations affected by the sudden changes in generation and load. The obtained result is better in comparison to the simulation results reported in the literature as in [7] where the author uses short time simulation and without consideration of the intermittent and stochastic nature of renewable sources. Besides the frequency deviations are small and more stable with the proposed method. This investigated method is an efficient choice to be applied to control the hybrid energy system frequency with the integration of renewable energy system under load change.

\section{REFERENCES}

[1] Ribeiro, L. D. S., et al., "Design, control, and operation of a hybrid electrical generation system based on renewable energy sources," Revista Eletrônica de Potência-Sobraep, vol. 15, no. 4, pp. 313-322, 2010.

[2] D. Lee and L. Wang, "Small-signal stability analysis of an autonomous hybrid renewable energy power generation/energy storage system part i: time-domain simulations," IEEE Transactions on Energy Conversion, vol. 23, no. 1, pp. 311-320, March 2008, doi: 10.1109/TEC.2007.914309.

[3] Tabatabaei, Naser Mahdavi, Ersan Kabalci, and Nicu Bizon, "Overview of Microgrid," Microgrid Architectures, Control and Protection Methods. Springer, Cham, pp. 3-19, 2020.

[4] A. Cagnano, E. De Tuglie, P. Mancarella, "Microgrids: Overview and guidelines for practical implementations and operation," Applied Energy, vol. 258, pp. 114039, 2020.

[5] H. A. Kazem, H. A. S. Al-Badi, A. S. Al Busaidi and M. T. Chaichan, "Optimum design and evaluation of hybrid solar/wind/diesel power system for Masirah Island," Environment, Development and Sustainability, vol. 19, pp. 1761-1778, 2017.

[6] A. H. A. Al-Waeli, et al., "Nanofluid based grid connected PV/T systems in Malaysia: A techno-economical assessment," Sustainable Energy Technologies and Assessments, vol. 28, pp. 81-95, 2018.

[7] S. K. Pandey, S. R. Mohanty, N. Kishora and J. P. S. Catalão, "Frequency regulation in hybrid power systems using particle swarm optimization and linear matrix inequalities based robust controller design," International Journal of Electrical Power \& Energy Systems, vol. 63, pp. 887-900, 2014.

[8] Ray, Prakash, Soumya Mohanty, and Nand Kishor, "Small-signal analysis of autonomous hybrid distributed generation systems in presence of ultracapacitor and tie-line operation," Journal of Electrical engineering, pp. 205214, 2010.

[9] M. Regad, et al., "Fractional order PID control of hybrid power system with renewable generation using genetic algorithm," 2019 IEEE 7th International Conference on Smart Energy Grid Engineering (SEGE), pp. 139-144, 2019, doi: 10.1109/SEGE.2019.8859970.

[10] I. Pan and S. Das, "Kriging based surrogate modeling for fractional order control of microgrids," IEEE Transactions on Smart Grid, vol. 6, no. 1, pp. 36-44, Jan. 2015, doi: 10.1109/TSG.2014.2336771.

[11] Indranil Pan and Saptarshi Das, "Fractional order fuzzy control of a hybrid power system with renewable generation using chaotic PSO," ISA Transactions, vol. 62, pp. 19-29, 2016.

[12] M. Regad, M. Helaimi, R. Taleb and A. E. Toubal Maamar, "Optimum synthesis of the PID controller parameters for frequency control in microgrid based renewable generations," Hatti M. (eds) Smart Energy Empowerment in Smart and Resilient Cities. ICAIRES 2019. Lecture Notes in Networks and Systems, vol 102, pp. 546-556, 2020, https://doi.org/10.1007/978-3-030-37207-1.

[13] T. Senjyu, T. Nakaji, K. Uezato and T. Funabashi, "A hybrid power system using alternative energy facilities in isolated island," IEEE Transactions on Energy Conversion, vol. 20, no. 2, pp. 406-414, Jun. 2005, doi: 10.1109/TEC.2004.837275. 
[14] Dulal Ch Das, A K Roy and N Sinha, "Genetic algorithm based PI controller for frequency control of an autonomous hybrid generation system," Proceeding International Multiconference of engineers and Computer scientists 2011, 2011.

[15] Pandey, Shashi Kant, Nand Kishor, and Soumya R. Mohanty, "Frequency regulation in hybrid power system using iterative proportional-integral-derivative Ho controller," Electric Power Components and Systems, vol. 42, no. 2, pp. 132-148, 2014.

[16] Naresh Kumari and A. N. Jha, "Frequency response enhancement of hybrid power system by using PI controller tuned with PSO technique," International Journal of Advanced Computer Research, vol. 4, no. 1, pp. 116-122, 2014

[17] M. Regad, et al., "Frequency control in microgrid power system with renewable power generation using PID controller based on particle swarm optimization," Hatti M. (eds) Smart Energy Empowerment in Smart and Resilient Cities. ICAIRES 2019. Lecture Notes in Networks and Systems, vol.102, 2020, doi:10.1007/978-3-03037207-1_1.

[18] Hossain, Shah Mohazzem, and M. S. A. A. F. Shiblee, "A review study on small signal stability enhancement in power system with integration of distributed wind energy sources," International Journal of Scientific and Engineering Research, vol. 8, no. 10, pp. 927-932, Oct. 2017.

[19] Li Wang, Dong-Jing Lee, Wei-Jen Lee, and Zhe Chen, "Analysis of a novel autonomous marine hybrid power generation/energy storage system with a high-voltage direct current link," Journal of Power Sources, vol. 185, no. 2, pp. 1284-1292, 2008.

[20] M. Willjuice Iruthayarajan and S. Baskar, "Evolutionary algorithms based design of multivariable PID controller," Expert Systems with applications, vol. 36, no. 5, pp. 9159-9167, 2009.

[21] Singh, Jayanti, et al., "Performance analysis of fractional order fuzzy PID controller for hybrid power system using WOA," 2018 2nd International Conference on Trends in Electronics and Informatics (ICOEI). IEEE, 2018.

[22] Mitchell, Melanie, "An introduction to genetic algorithm," MIT press, 1998.

[23] Sharaf, Adel M., and A. A. El-Gammal. "A novel efficient PSO-self regulating PID controller for hybrid PV-FCdiesel-battery micro grid scheme for village/resort electricity utilization." 2010 IEEE Electrical Power \& Energy Conference. IEEE, 2010.

[24] Latif, A., Das, D. C., Ranjan, S., \& Hussain, I., "Integrated demand side management and generation control for frequency control of a microgrid using PSO and FA based controller," International Journal of Renewable Energy Research (IJRER), vol. 8, no.1, pp. 188-199, 2018.

\section{BIOGRAPHIES OF AUTHORS}

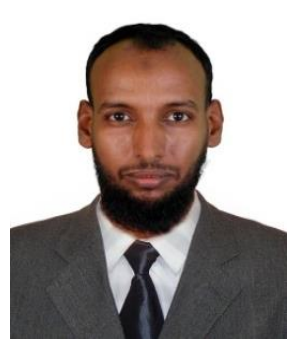

Regad Mohamed received his Master degree with first class of honor in Electrical Engineering Systems from the University of Mascara Algeria in 2016 respectively. He is currently pursuing his Ph.D. degree in electrical power and high voltage at Hassiba Benbouali University of Chlef, Algeria. His research interest focuses on modeling and optimal control of the electrical power system, along with heuristics optimization techniques.

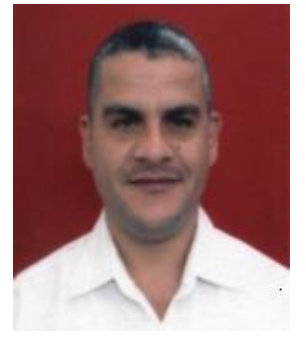

M'hamed Helaimi was born in Chlef, Algeria, in 1976. He received the Engineer Degree (with honors) and the Magister Degree, in Electrical Engineering from the University of Chlef, Algeria, in 2001 and 2004, respectively. In 2004, He joined the Department of Electrical Engineering, University of Chlef, where, from 2004 to 2014, He was a research assistant. He received the Ph.D. degree in Electrical Engineering from the University of Sciences and technology of Oran, Algeria, in 2014. He is researcher member in the Laboratory of Electrical Engineering and Renewable Energy since 2011. His scientific work is related to induction heating application and drives, genetic algorithm, artificial intelligence, non linear control, dynamic modeling, DSP processor, FPGA and power electronics.

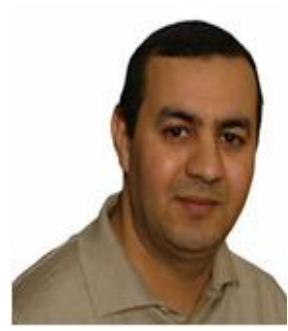

Rachid Taleb received the M.S. degree in Electrical Engineering from the Hassiba Benbouali University, Chlef, Algeria, in 2004 and the Ph.D. degree in Electrical Engineering from the Djillali Liabes University, Sidi Bel-Abbes, Algeria, in 2011. Currently he is a professor in the Department of Electrical Engineering, Hassiba Benbouali University. He is a team leader in the LGEER Laboratory (Laboratoire Génie Electrique et Energies Renouvelables). His research interest includes intelligent control, heuristic optimization, control theory of converters and converters for renewable energy sources. 